\title{
Attitudes of Children Towards Augmentative and Alternative Communication Systems
}

\author{
Margaret Lilienfeld \\ Occupational therapist
}

\author{
Erna Alant \\ Director
}

\author{
Centre for Augmentative and Alternative Communication \\ University of Pretoria, \\ South Africa
}

\begin{abstract}
The purpose of this study was to determine the impact of voice output, as a characteristic of a child's AAC system, on the attitude of unfamiliar peers. The need to develop a suitable tool to measure the attitudes of peers led to the development of the Communication Aid/Device Attitudinal Questionnaire (CADAQ). A descriptive survey design was used and the suitability of the CADAQ was tested in a pilot study. One hundred and fifteen participants, aged $11-13$ years, viewed a videotape of a 13-year-old boy with cerebral palsy, communicating with the use of an AAC device. Attitudes were measured according to three dimensions: affective/behavioural, cognitive/belief and communication competence. Data were analysed with a 2 (group) $x 2$ (gender) $\times 3$ (dimension) analysis of variance (ANOVA) with $\propto=05$. An item analysis, Cronbach Alpha's and scale intercorrelations between the 3 dimensions of the CADAQ were computed to determine the internal consistency of the CADAQ. Results reflected more favourable atritudes to the presence of voice output in comparison to the no voice option. Girls held more positive attitudes to the peer with disabilities and litlle or no functional speech (LNFS). Good internal consistency of the CADAQ was demonstrated.
\end{abstract}

KEY WORDS: Attitudes, augmentative and alternative communication (AAC), voice output, peers, interaction, communication.

\section{INTRODUCTION}

The use of Augmentative and Alternative Communication (AAC) systems provides children with little or no functional speech (LNFS) the opportunity to engage in the communicative process. The attitudes of communication partners, particularly peers, have a significant influence on the success of AAC intervention (Kraat, 1987). The need to increase our knowledge, not only of the processes that occur when AAC users interact with speaking partners but also of how features of various AAC systems impact on the interaction has been highlighted (Light, 1988). Evidence that communication device characteristics e.g. voice output, have a significant effect on the attitude and perceptions of partners and their willingness to interact with the user has been widely described (Gorenflo \& Gorenflo, 1991; Hoag \& Bedrosian, 1992; O'Keefe, Brown \& Schuller, 1998).

Insufficient interaction between children who use $A A C$ and their peers is well documented as negatively affecting the formation of attitudes (Beukelman \& Mirenda, 1992; Goossens, Crain \& Elder, 1994; Kraat, 1987; Lloyd, Fuller \& Arvidson, 1997). Peer attitudes and perceptions towards children using AAC devices necessitate a more systematic understanding of factors that contribute to the formation of attitudes in children. As these factors may well differ from those of adults and adolescents, the variables that affect peer perceptions of the communicative competence of children who use AAC need to be investigated empirically in order to develop successful intervention strategies. One of these variables, the impact of the AAC device used and the way in which a device improves or diminishes the speaking partner's perception of the user, is of special interest (Higginbotham, 1989; Schepis \& Reid, 1995).

O'Keefe et al. (1998) found that the AAC user is more likely to be favourably considered by peers when the aided message is highly intelligible, socially appropriate, and reflects the intelligence, age and gender of the user. Use of intelligible voice output has major advantages for the communication partner (Beukelman \& Mirenda, 1992). The views of AAC users, on whether voice output has an effect on their interactions with peers, were elicited by the researcher (first author) through the medium of the ACOLUG listserve on the Internet, $\mathrm{AAC}$ users expressed the view that voice output 
provided a natural, typical means of communication that had advantages over other methods of augmented communication (K. Spivey, personal communication, November 19, 1998; M. A. Merchen, personal communication, November 19, 1998). Provision of voice output was perceived as allowing users to express their personalities and their sense of humour as well as allowing them to approach strangers (K. McMaster, personal communication, November 19, 1998; M. A. Merchen, personal communication, November 19, 1998). In addition, voice output was credited with improving the confidence and self-image of users (M. A. Merchen, personal communication, November 19, 1998).

The crucial issue is whether peers rate a child who uses an AAC device that produces speech (voice output) as more competent than a child who uses a low technological device without voice output. Evidence for this appears to be controversial. Reports by AAC users as highlighted by $\mathrm{K}$. Spivey (personal communication, November 19, 1998), K. McMaster (personal communication, November 19, 1998) and M.A. Merchen (personal communication, November 19, 1998) and the experience of clinicians suggest that voice output will have a positive effect on the attitudes of peers towards a child with disabilities who uses an AAC device. Research with adults in support of this hypothesis includes a study by Schepis and Reid (1995). In this study support staff increased their interactions with a 23 -year-old adult with disabilities and LNFS in both adult education and residential settings when the young adult had access to a voice output communication aid (VOCA). In addition, results of a study to assess the attitudes of undergraduate college students toward a peer with physical disabilities and LNFS indicated that when the VOCA was used, peer evaluations were more favourable than when unaided or alphabet board techniques were used (Gorenflo \& Gorenflo, 1991).

Conversely, the research of Blockberger, Armstrong, O'Connor and Freeman (1993) indicated that the attitudes of fourth-grade children (aged nine and 10 years) toward a child with LNFS was not more positive when an aided electronic technique (a VOCA) was used as opposed to when aided non-electronic or unaided techniques were used. Similarly, the research of Beck and Dennis (1996) indicated that the type of augmentative aid (a non-electronic alphabet board vs. a voice output device) used by a child with physical disabilities and LNFS was not associated with a difference in fifth-grade peer attitudes. This finding was confirmed in a more recent study on attitudes of third to fifth-grade children towards their peers who use AAC devices (Beck et al., 2000). No effects of physical status or AAC technique (a VOCA vs. a picture communication board) on the attitudes of the peers were found (Beck et al., 2000). The authors suggested that a larger sample size as well as different stimulus material (for example, a

- videotape or a real-life exposure rather than a picture of a child in a wheelchair) may have resulted in more differentiated reactions.

With the adoption of educational policies that favour the inclusion of children with disabilities in schools (NCSCET, 1997) in South Africa, it is important that we investigate the attitudes of peers to children who use AAC. Social communicative abilities may have a greater impact than academic abilities on the success of inclusion of a child with disabilities (Carter \& Maxwell, 1998). Functional communication systems for children will impact significantly on their social as well as academic performance in the classroom. A survey by Alant (1999) of students attending schools for children with severe mental disabilities in the Pretoria area, South Africa, indicated that approximately $39 \%$ of these children had LNFS. Possible factors contributing to this high incidence included the lack of early intervention, little or no access to therapeutic services and the limited knowledge and insufficient training of teachers. The survey reflected a lack of access to augmentative and alternative communication (AAC) systems by children with LNFS and low teacher expectations of students with LNFS (Alant, 1999). In addition, both teachers and parents expressed concern about the attitudes of regular school students toward the children with LNFS (Alant, 1999).

Even though educational policies in South Africa support social inclusion, (NCSCET, 1997) few students with LNFS are presently included in mainstream schools. In order to facilitate the inclusion of children with LNFS in mainstream schools an in-depth understanding of the attitudes of regular students towards peers with LNFS seemed pivotal.

Negative attitudes of people in developing countries towards those with disabilities have been reported (Goerdt, Helander, Mendis \& Nelson, 1989; Kisanji, 1995). Attitudes determine with whom, about what, where and how individuals interact with others. This profound effect of attitudes on interactions highlights the need to determine the attitudes of non-disabled peers to children with disabilities, including those with LNFS.

Attitudes are, however, difficult to measure accurately and researchers have developed and employed many different methodologies and techniques in attempting to quantify attitudinal responses. Researchers studying the perceptions and attitudes of adults and children toward AAC users have used Likert-type attitudinal questionnaires and rating scales (Beck \& Dennis, 1996; Bedrosian, Hoag, Calculator \& Molineux, 1992; Gorenflo \& Gorenflo, 1991; Gorenflo \& Gorenflo, 1997; Hoag, Bedrosian, Johnson, \& Molineux, 1994).

A theoretical construct appropriate to understand children's attitudes to peers with a disability is the $A B C$ model of attitudes (Feldman, 1993). The model suggests that any attitude has three interrelated elements, namely an affective, a behavioural and a cognitive component (Feldman, 1993). Although the potency of the link between an attitude and the resultant behaviour' does vary, people generally endeavour to maintain consistency between their attitudes and behaviour, which form a logical behavioural framework (Feldman, 1993).

The Chedoke-McMaster Attitudes toward Children with Handicaps (CATCH) scale used by Beck and Dennis (1996) and Blockberger et al. (1993) was based on the theoretical construct that attitudes have an affective, a behavioural and a cognitive (belief) component (Rosenbaum, Armstrong \& King, 1986). However, factor analysis indicated that a two component model was more appropriate, namely affective/behavioural and cognitive (Rosenbaum et al., 1986). The sensitivity of the $\mathrm{CATCH}$, which was developed for a more general purpose, was queried in terms of its suitability for differentiating attitudes 
towards various AAC techniques used by children (Beck \& Dennis, 1996). Beck and Dennis (1996) suggested that future research include the development of a scale designed to measure subtle differences in children's attitudes to AAC users.

In order to develop a scale, the attitudinal questionnaires and scales used by researchers to determine attitudes toward adult AAC users were also considered. These included the Attitudes Toward Nonspeaking Persons Scale (ATNP) used by Gorenflo and Gorenflo (1991) and a questionnaire for use in their study on variables influencing perceptions of an adult AAC user. Factor analysis of the ATNP highlighted two meaningful attitudinal factors: a "general evaluation" corresponding to the cognitive component, and the "interactive/affective" factor corresponding to the affective/behavioural component of the CATCH (Gorenflo \& Gorenflo, 1991). The questionnaire by Bedrosian et al. (1992), a Likert-type scale, consisted of 30 items and was designed specifically to assess the perceived communicative competence of AAC users.

The recent study by Beck et al. (2000) describes the Assessment of Attitudes Toward Augmentative/Alternative Communication (AATAAC), a new measuring instrument for determining attitudes of children towards AAC users. Although the AATAAC was not yet published or available at the time the present study was conducted, there are some interesting similarities and differences to the scale, the CADAQ, used in this study. Both the AATAAC and the CADAQ are 5-point Likert-type rating scales with some items positively and other items negatively worded, the former consisting of 26 and the latter 37 items. The AATAAC contained 7 cognitive aspect items, 5 affective aspect items and 14 items to measure behavioural intents (Beck et al., 2000). The first page of the AATAAC also contained six pictures of facial expressions as a "supplemental, non-verbal measure of affective responses" (Beck et al., 2000, p.16). Possibly the most salient difference between the two scales is the inclusion of a section of 13 items on the rating of the communication competence of the AAC user in addition to 13 affective/behavioural items and 11 cognitive items in the CADAQ.

A further aspect of analysis of attitude to disability has been across age and gender. Findings have been inconsistent. Several studies found that girls have more favourable attitudes to disabled peers than boys do (Fiedler \& Simpson, 1987; Rosenbaum et al., 1986; Voeltz, 1980). An exception was a study of children's ratings of peers presented as intellectually and physically disabled which reported that boys gave more favourable ratings than girls (Wisely \& Morgan, 1981). Although not a major aim of the study, the recent study by Beck et al. (2000) suggested the attitude of peers (girls and boys), exposed to children with disabilities, towards children with LNFS may become less favourable as they became older.

Research on the effect that voice output has on the attitudes of peers of children with disabilities is conflicting (Beck \& Dennis,1996; Blockberger et al., 1993; Gorenflo \& Gorenflo, 1991; Schepsis and Reid, 1995). As children with LNFS may now be included in mainstream education in South Africa it is imperative to investigate how this process may be facilitated. It is important to identify any variable that influences the initial attitudes of peers to a child who uses AAC to ensure that initial perceptions are as affirmative as possible (Beck et al. 2000). The present study addressed the question of whether the variable of speech output, as a feature of the output mode of a communication device, has an effect on the attitudes of children towards a peer with disabilities and LNFS.

\section{METHODOLOGY}

\section{AIMS}

The primary aim was to develop a suitable tool, the Communication Aid/Device Attitudinal Questionnaire (CADAQ) to measure any difference in the attitudes toward children who are AAC users, dependent on the output mode of the devices used.

The following objectives were formulated:

To establish the suitability of the CADAQ by determining the internal consistency, content validity and construct validity.

To use the CADAQ to investigate whether voice output had an effect on the attitudes of children, 11-13 years of age, toward an unfamiliar peer with LNFS.

To determine whether the attitudes of boys differed from girls towards a peer with physical disabilities and LNFS who uses an AAC system.

\section{RESEARCH DESIGN}

A descriptive survey design was used to compare children's responses to a peer, with physical disabilities and LNFS, depending on whether the peer used an AAC device with voice output or not. Purposive sampling, a non-probability sampling procedure, was utilised by the study (Dooley, 1995) as the subjects were selected according to their age and grade level as well as for reasons of geographical convenience. This was in accordance with the characteristic of a descriptive survey that the population must be deliberately chosen, precisely defined and explicitly circumscribed to ensure precise parameters (Leedy, 1985).

\section{SUBJECTS}

Permission from parents and the educational authority was received for the participation of 115 children from a mainstream, suburban, co-educational (boys and girls) Senior Primary School in KwaZulu-Natal, South Africa. The medium of instruction at the school was English. Children with severe disabilities were not integrated into this school and pupils were generally from a middle class socio-economic background. Although, only learners receiving their education in English were included, this criterion included learners of different home languages. Ninety four percent of the children were from families whose home language was English and seven children (5.51\%) were from families where the home language was not English. Of these, five pupils came from Zulu speaking families, one from an Afrikaans speaking family and one from a family where Polish was the home language.

All subjects were between 11 years, 0 months and 13 years, 6 months of age, in Grade 6 or 7, and were rated 
by their teachers as having an adequate vocabulary and knowledge of language to understand the questionnaire statements. When the researcher inquired about previous exposure to people with disabilities, only one child reported having a family member with a significant disability. None of the other children reported knowing any person with significant disabilities. This was not surprising as no children with severe disabilities were included in the school.

\section{MATERIALS}

\section{The Videotapes}

Videotapes of a child with LNFS using an AAC device, a DeltaTalker ${ }^{\mathrm{TM}}$ in spell mode with a simple alphabet overlay were recorded. The videotape was filmed using a NS5 SVHS Panasonic ${ }^{\mathrm{TM}}$ camera on a Techoni $^{\text {TM }}$ Super High Grade Videotape. One videotape, Videotape A, showed the child communicating with the device with synthetic voice output, the Dectalk "Perfect Paul" option. A copy of this videotape was made without the voice output of the DeltaTalker ${ }^{\mathrm{TM}}$ and this was identified as Videotape B.

Care was taken to ensure conformity between using an alphabet board and a voice output communication device (VOCA). Conformity was achieved by using the DeltaTalker $^{\mathrm{TM}}$ in spell mode for closer comparison to an alphabet board and to eliminate the variable of message encoding rate. A special overlay showing only the letters of the alphabet in QWERTY arrangement and numbers $0-9$ was used.

The child with LNFS was a 13-year-old male with cerebral palsy whose home language was English. Cognitively intact, he was a competent communicator using a DeltaTalker ${ }^{\mathrm{TM}}$ and was proficient at spelling out his messages as he used an alphabet board prior to obtaining his device. "Kim", the peer, was a 15-year-old female teenager who had previously met the AAC user. Her role was that of a conversational partner.

The content of the videotape was that of a conversation between "Alan", the AAC user, and "Kim". At the beginning of the videotape 'Alan' was viewed from the front. He was not wearing his head pointer and smiled briefly at the camera. For the remainder of the videotape the camera was positioned above and behind 'Alan's' left shoulder. In the videotape 'Alan's' shoulder, the left side of his head and helmet, as well as the head pointer and the communication device were visible. The letters on the overlay and each letter selected by the user as he. spelt out his messages, were clearly visible. Unable to walk, he was seated in a manual wheelchair during the videotaping. The peer was not seen on the videotape, although her voice was heard. This strategy maintained the focus on the AAC user and further reduced any possible variables due to "Kim's" appearance. The speaking partner did not use re-auditorizations as the variable of voice (in the no-voice option) would otherwise be introduced. Furthermore, Videotape B more clearly reflects the reality of communication with an alphabet board user (an extract of the conversation is contained in Appendix B).

\section{The Development of the Measuring Instrument}

The CADAQ was devised for children, 11-13 years (grades 6-7), to measure their attitudes towards the AAC user. The questions were devised to measure the following three dimensions:

- The affective/behavioural components of attitudes

- The cognitive components of attitudes

- The evaluation of communicative competence.

Fifteen of the twenty-four questions examining the affective/behavioural and cognitive dimensions of attitudes included in the CADAQ were based on the $\mathrm{CATCH}$. The CATCH was developed according to the three-dimensional model of attitude formation, that attitudes consist of interrelated affective, behavioural intent and cognitive components (Rosenbaum et al., 1986). Several of the questions pertaining to communicative competence were re-worded from the questionnaire designed by Bedrosian et al. (1992) to measure the communicative competence of adult AAC users.

In the CADAQ, statements were written so that agreement represented either a favourable or unfavourable attitude with respect to the variable being assessed. To prevent the acquiescence type of response, half of the questions in the attitude scale were worded in a positive form and half in the negative form. Short closed questions were used to facilitate ease of completion. Items were arranged in a random order and participants were asked to rate each item using a fivepoint scale ranging from one, 'I strongly agree' to five, 'I strongly disagree'. Scores from 1 to 5 were assigned for each item. As high scores on the scale indicated more positive attitudes and low scores more negative attitudes, positive responses to positive items as well as negative responses to negative items were assigned higher scores as was suggested by Oppenheim (1973).

Validity and Reliability of the Questionnaire

Six teachers of Grades 6 and 7 rated the statements as applicable and relevant to the experiences of children of that age group thereby providing information on the face validity of the measure. The teachers also rated the vocabulary and grammar as appropriate but suggested that the statements be read to the participants by the researcher because children with specific reading difficulties may be present in Grade 6 and 7 classes.

Construct validity is the extent to which the scale measures the theoretical concept of interest (Dooley, 1995). Construct validity of the CADAQ was established by predicting that girls would have more positive attitudes than boys would. This prediction was based on previous research indicating that girls have more positive attitudes to peers with disabilities (Fiedler \& Simpson, 1987; Rosenbaum et al., 1986; Voeltz 1980).

Pilot Study

A preliminary form of the CADAQ consisting of 40 items was tested in a pilot study. The objective of the pilot study was to identify any potential problems with the practicality or feasibility of the questionnaire, the videotapes and the proposed procedures. The 68 pilot study subjects consisted of equal numbers of boys and girls, aged between 11 years 0 months and 13 years 6 months, from Grades 6 and 7 at a co-educational (girls and boys) English medium, Senior Primary school 
situated in the Inner West Municipal area of Durban, KwaZulu-Natal, South Africa. These subjects were selected to ensure similar educational, home language, socio-economic and geographical status as the main study subjects. This was done to facilitate the identification of possible difficulties, as the pilot study subjects would have a similar understanding of questionnaire statements to the main study subjects.

\section{Results of the Pilot Study}

Modifications to the CADAQ following the pilot study included the elimination of three statements and the order of some of the statements was changed to make certain that rephrased pairs were widely spaced. The final questionnaire consisted of 37 items (see Appendix A). In addition the videotapes were re-filmed in a quieter environment to eliminate extraneous noise.

\section{PROCEDURE}

Four class groups, two Grade 6 and two Grade 7 classes were randomly selected to take part in the main study. Thereafter, one Grade 6 and one Grade 7 class were randomly assigned to form Group 1. The second Grade 6 and the second Grade 7 class were combined to form Group 2. The groups were considered comparable in terms of gender and age. In Group 1, 31 (54\%) subjects were girls and $26(46 \%)$ were boys and in Group $2,32(55 \%)$ were girls and $26(45 \%)$ were boys. In Group 1 , twenty-six participants were 11-year-olds, twenty-six were 12 -year-olds and five were 13 years old. The age distribution of Group 2 included twenty-nine 11-year-old subjects, twenty-six 12-year-old and three 13-year-old subjects. The class teachers and head of department for grade 7 rated the groups as comparable in terms of academic achievement based on grade tests and assignments.

Group 1 was assigned to view videotape A and Group 2 , videotape B. Both groups completed the questionnaire on the same day before recess to minimise fatigue and to ensure that no discussion took place between the subjects.

\section{DATA COLLECTION}

The data was collected in the group teaching room, which easily accommodated the two classes making up each group. The room had tiered seating and a large screen episcope to ensure excellent viewing of the video. The researcher gave identical instructions to each group of subjects before showing the videotapes. (see Appendix $\mathrm{C}$ for the instructions). The questionnaires were then distributed and subjects given further instructions. The two trial items were then presented and the subjects indicated they understood what was required. One trial item was positively stated and one negatively stated.

Following the teachers' advice, each of the 37 statements of the questionnaire was read aloud prior to the subjects completing it. After completion of the last statement the subjects were requested to make sure all statements had been responded to before the questionnaires were collected. The subjects were then thanked and their questions regarding peers with disabilities were addressed.

\section{DATA ANALYSIS}

The mean of the total scores on the CADAQ and for each of the three dimensions was calculated for each group (voice and no voice) as was the mean for the total of the girls' and the boys' scores within each group. To give an idea of the degree of variance from the mean, standard deviations for the total and the three dimensions were computed for both groups as well as for girls' and boys' scores. Frequencies for each scoring category (15) were calculated for each individual variable. An analysis of variance (ANOVA) of the total scores and the three dimension scares was completed to determine if there were significant differences between the voice and no voice groups, girl's and boy's responses within groups, as well as to determine if there was any interaction between group and gender. Item analysis, Cronbach's Alpha and correlations between the three dimensions of the scale were all calculated to determine the internal consistency and reliability of the CADAQ.

\section{RESULTS}

Scores from 1(negative) to 5 (positive) were assigned for each of the 37 items on the CADAQ. The three components tested were affective/behavioural, cognitive and communicative competence with 13,11 and 13 items respectively. Reliability implies consistency in differentiating among persons and can be gauged by the consistency of scores (Dooley, 1995). One measure of reliability is internal consistency, which indicates both the degree to which the items concur with each other and the conformity of items relative to overall performance on the questionnaire.

The internal consistency of the CADAQ with respect to the concurrence of items to each other was determined by item analysis using the ITEMAN programme (Assessment Systems Corporation). Item scale correlations for the affective/behavioural component varied between .48 and .81, apart from item 26 ("I feel upset when I see how Alan has to 'talk"'). This item was ambiguous and should have been eliminated after the field test study. The Item scale correlations are above .27 , which is indicative of acceptable internal consistency for the13 items (Owen \& Taljaard, 1995): As there were 11 items on the cognitive component item scale, correlations of .3 or higher reflect acceptable levels (Owen \& Taljaard, 1995). The item scale correlations on the cognitive component varied between .42 and .79 indicating good internal consistency. The item scale correlations of the communicative competence items varied between .34 and .76 reflecting good internal consistency as item scale correlations of .27 or above indicate acceptable correlation for a 13 item subscale (Owen \& Taljaard, 1995).

Reliability based upon the consistency of subjects' responses to all items in a subscale was determined by Cronbach's coefficient alpha, as this method is used most often for questionnaires in which items have 3 or more answer options to measure test reliability (Dooley, 1995). An acceptable level for reliability is .80 . The reliability for the affective/behavioural component was .89 for the 
voice option and .85 for the no voice group. The reliability for the cognitive component was .81 and .77 for voice and no voice groups respectively. Reliability for the communicative competence component was .84 for the voice group and .76 for the no voice group. As mentioned earlier, the deletion of item 26 in the affective/behavioural component would improve the reliability coefficient of this component.

Correlations between the three components of the scale (attitude/behavioural, cognitive and communicative competence) were computed. All the correlations were positive and significant at the 5\% level indicating that these components are closely related and do form integral subscales of the same attitudinal scale. The correlations are presented in Table 1. Notably, the correlation between the various components is not as high for the no voice option as for the voice option, indicating less consistency in the responses of the participants who watched the no voice option.

Table 1: Comparison of component intercorrelations.

\begin{tabular}{|l|l|l|l|l|l|l|}
\hline \multicolumn{2}{|l|}{ VOICE $(\mathrm{n}=57)$} & \multicolumn{2}{l|}{ NO VOICE (n=58) } \\
\hline \multicolumn{2}{|l|}{ Component } & \multicolumn{2}{l|}{ Component } \\
\hline & 1 & 2 & 3 & 1 & 2 & 3 \\
\hline 1 & 1.000 & 0.727 & 0.666 & 1.000 & 0.591 & 0.491 \\
\hline 2 & 0.727 & 1.000 & 0.739 & 0.591 & 1.000 & 0.562 \\
\hline 3 & 0.666 & 0.739 & 1.000 & 0.491 & 0.562 & 1.000 \\
\hline
\end{tabular}

Note: $\quad 1=$ Affective/ behavioural component

$2=$ Cognitive/belief component

$3=$ Communicative competence component

To determine whether group (voice or no voice) and gender influenced attitudes, 2 (group) $\times 2$ (gender) analysis of variance (ANOVA) was conducted with the total scores and the scores of the three components of the CADAQ as dependent variables. The group (voice output or no voice output) and the gender (male or female) were the independent variables. The level of significance was $\propto=0.05$. Significant effects were found for both group and gender as reflected in the table below.

Table 2: Analysis of variance results for group (output mode) and gender

\begin{tabular}{|c|c|c|c|c|c|}
\hline & \multicolumn{5}{|l|}{ Group } \\
\hline & \multicolumn{2}{|c|}{$\begin{array}{l}\text { Group } 1 \text { - Voice Output } \\
57 \text { in Group }\end{array}$} & \multicolumn{2}{|c|}{$\begin{array}{l}\text { Group } 2 \text { - No Voice Output } \\
58 \text { in Group }\end{array}$} & \multirow{2}{*}{$\begin{array}{l}\begin{array}{l}\text { Group } \\
\text { Comparison }\end{array} \\
\text { p-value }\end{array}$} \\
\hline & Mean & $\begin{array}{l}\text { Standard } \\
\text { Deviation }\end{array}$ & Mean & $\begin{array}{l}\text { Standard } \\
\text { Deviation }\end{array}$ & \\
\hline $\begin{array}{l}\text { Total Scores on } \\
\text { CADAQ }\end{array}$ & 116.44 & 20.51 & 104.91 & 16.29 & $.0008^{*}$ \\
\hline $\begin{array}{l}\text { Affective/ } \\
\text { Behavioural }\end{array}$ & 45.28 & 8.68 & 41.67 & 7.48 & $.0132 *$ \\
\hline $\begin{array}{l}\text { Cognitive/ Belief } \\
\text { Component }\end{array}$ & 31.54 & 6.82 & 30.64 & 5.98 & .4577 \\
\hline \multirow{4}{*}{$\begin{array}{l}\text { Communi -cative } \\
\text { Competence }\end{array}$} & 39.61 & 7.33 & 32.60 & 6.01 & $.0001 *$ \\
\hline & \multicolumn{5}{|l|}{ Gender } \\
\hline & \multicolumn{2}{|l|}{$\begin{array}{l}\text { Girls } \\
63 \text { in Group }\end{array}$} & \multicolumn{2}{|c|}{\begin{tabular}{|l|} 
Boys \\
52 in Group
\end{tabular}} & Group Comparison \\
\hline & Mean & $\begin{array}{l}\text { Standard } \\
\text { Deviation }\end{array}$ & Mean & $\begin{array}{l}\text { Standard } \\
\text { Deviation }\end{array}$ & p-value \\
\hline $\begin{array}{l}\text { Total Scores on } \\
\text { CADAQ }\end{array}$ & 115.57 & 16.15 & 104.63 & 16.15 & $.0013^{*}$ \\
\hline $\begin{array}{l}\text { Affective/ } \\
\text { Behavioural }\end{array}$ & 45.46 & 6.80 & 41.04 & 9.25 & $.0031 *$ \\
\hline $\begin{array}{l}\text { Cognitive/ Belief } \\
\text { Component }\end{array}$ & 32.59 & 5.75 & 29.27 & 6.72 & $.0052^{*}$ \\
\hline $\begin{array}{l}\text { Communicative } \\
\text { Competence }\end{array}$ & 37.52 & 6.53 & 34.32 & 8.34 & $.0092^{*}$ \\
\hline
\end{tabular}

$=$ significant at the $5 \%$ level 
As reflected in Table 2 the means of total scores of the CADAQ and the scores on the affective, cognitive and communicative competence components indicate that girls expressed significantly more favourable attitudes to the disabled peer with LNFS than boys.

Statistically significant differences were evident in favour of the voice option in the total score as well as on the affective/behavioural and the communicative competence component scores. Although not significant, the same tendency is reflected on the cognitive component scores. The interaction between gender and group was also investigated but was not found to be significant.

\section{DISCUSSION}

Results indicated that the CADAQ has good internal consistency, content validity and construct validity. Deletion of statement 26 would improve the internal consistency. The CADAQ proved to be sensitive to differences in peers' attitudes towards a child with disabilities using an AAC device with and without voice output. The research subjects readily understood and identified with the statements of the CADAQ.

Peer attitudes as reflected in the results were more positive when voice output was used and this result correlates with the findings of Gorenflo and Gorenflo (1991). In their study peer evaluations of young adults were more favourable when a VOCA was used than when unaided or alphabet board techniques were used (Gorenflo \& Gorenflo 1991).

The current findings differ from those of investigations by Blockberger et al. (1993) and Beck and Dennis (1996). Blockberger et al. (1993) found the AAC technique used (unaided, alphabet board and VOCA) had no perceivable impact on the attitudes of the fourth graders in their study. As in the current study, classes of children viewed videotapes of a peer with physical difficulties who had LNFS. The peers' attitudes were measured using the CATCH scale (Blockberger et al. 1993). Beck and Dennis (1996), in their research on the attitudes of fifth graders towards a peer with physical disabilities and LNFS who used AAC, found no difference in CATCH scores between those who viewed the videotape of the child using the non-electronic device and those who viewed the child using the VOCA. The videotape subject in their study, a boy, used a combination of gestures, verbalisations and pointing to an alphabet board in the non-electronic (low technological) option and a combination of gestures, verbalisations and a Touch Talker $\mathrm{TM}$ in the high technological option.

It is difficult to substantiate the precise reason for the difference in outcomes between the studies, as there are several methodological differences which merit discussion.

\section{Differences in the Measuring Instruments.}

The CADAQ statements referred to the names (pseudonyms) of the videotape subjects whereas the CATCH refers to the more generic term of "handicapped" children (Rosenbaum et al., 1986). Unlike the CATCH, the CADAQ included 13 statements on the communication competence of the child using AAC (See
Appendix A). These differences may have helped the peers completing the CADAQ to identify more closely with the AAC user and his skill in communicating.

\section{Differences in the Videotapes.}

In an attempt to isolate the variable of voice output in the current study the first tape (videotape A) was dubbed sans the voice output of the VOCA, to create Videotape $B$. The tapes were thus identical visually and in terms of topic of conversation and number and length of message turns. Three separate videotapes were filmed corresponding to each AAC technique (unaided, alphabet board and VOCA) (Blockberger et al. 1993). The strategies of using a scripted conversation and editing were employed to control discrepancies in topic and message selection rate. In the Beck and Dennis (1996) study, two videotapes were filmed and these were edited to form two 5-minute conversational samples that were as similar as possible. In the first tape the video subject gestured, verbalised and pointed to an alphabet board and in the second videotape he used a combination of gesturing, verbalising and using a VOCA (Beck \& Dennis 1996).

The physical appearance of the AAC user could influence the initial attitudes of peers (Blockberger et al. 1993). The videotape subjects were different for each of the studies. In the Blockberger et al. (1993) study the child with LNFS was an attractive 9-year-old girl, in the Beck and Dennis (1996) study a 13-year-old boy who smiled, laughed and occasionally drooled and in the current study a 13-year-old boy who accessed his VOCA with a head pointer. In addition, the conversational partners in all three studies also varied. Adult female therapists were used in both the Blockberger et al. (1993) and the Beck and Dennis (1996) studies whereas a teenage female peer was used in the current study.

The intelligibility, age- and gender-appropriateness of synthetic voice output influences the attitude of listeners and negative attitudes may result when VOCAs are first introduced to peers (Mirenda, Eicher \& Beukelman 1989). Different devices with diverse speech options were used in each of the studies during the high technology option. A Prentke Romich Touch talker TM was used in the Beck and Dennis study (1996), an ACS Epson HX-20 ${ }^{\mathrm{TM}}$ in the Blockberger et al. (1993) study and a Prentke Romich DeltaTalker ${ }^{\mathrm{TM}}$ in the present study.

A final aspect to consider with regard to the videotapes is that the strategy of re-auditorization was used in both the Blockberger et al. (1993) and Beck and Dennis (1996) investigations but not in the current study and this could have impacted on the results obtained.

\section{LIMITATIONS AND FUTURE RESEARCH}

There are several limitations to the present study. The subjects were from a limited urban geographical area and represented a narrow socio-economic group. Accordingly results can only be generalised to this group. The small number of subjects $(\mathrm{N}=115)$ also limited the statistical procedures that could be applied. It was, for example, not possible to do a factor analysis of the items of the questionnaire. The study also used only one child with physical disabilities and LNFS, and different results 
toward a different AAC user may have possibly been revealed, as initial attitudes are influenced by factors such as physical attractiveness, gender and attire.

Directions for future research should include the interaction of the device used with other factors that are known to be important in the formation of initial attitudes of children to peers e.g. physical appearance (Blockberger et al. 1993). The design and critical evaluation of peer training programmes to improve the interaction of peers with. children with LNFS will enhance our understanding of peer attitudes and interactions with children who use AAC. It is essential to include AAC users and their views must be considered not only in determining appropriate intervention but also relevant research.

\section{CONCLUSION}

A significant difference between the mean of total scores of the groups supported the hypothesis that the attitudes of children to peers with physical disabilities who have LNFS are significantly more positive when the communication device used has voice output. This result supports the provision of a device with voice output as a means of promoting more favourable initial peer attitudes towards a child with disabilities and LNFS. A device however, is only part of the equation to promote the interaction of a child with disabilities and LNFS with peers. The peer partners and the AAC user should receive training and be taught strategies to promote successful interactions. Facilitation of interaction between peers and the AAC user should be continued until spontaneous, functional and independent communication readily takes place.

Peer perceptions and attitudes are important to the personal and educational progress of all students including those with LNFS. The crucial role that peers can assume in the education of all pupils, disabled or not, through peer tutoring and support strategies is increasingly recognised (Uditsky, 1993). As we progress towards inclusion of children with LNFS into community schools in South Africa, an in-depth understanding of factors impacting on the process remain pertinent to enhance intervention efforts.

\section{ACKNOWLEDGEMENTS}

This article is based on a Master's dissertation entitled "The Attitudes of Children to Unfamiliar Peers Using Augmentative and Alternative Communication Devices", written by the first author in partial fulfilment of the requirements for a Master's degree in Alternative and Augmentative Communication at the University of Pretoria, South Africa. The promoter of the degree was Prof. E. Alant. Special thanks to Mrs Rina Owen, Department of Research Support, at the University of Pretoria for statistical support.

\section{REFERENCES}

Aiken, L. R. (1996). Rating Scales and Checklists. Evaluating behavior, personality and attitudes. New York: John Wiley \& Sons Inc.

Alant, E. (1999). Students with little or no functional speech in schools for students with severe mental retardation in South Africa. Augmentative and Alternative Communication, 15(2), 83-94.

Beck, A. R., \& Dennis, M. (1996). Attitudes of children toward a similar-aged child who uses Augmentative Communication. Augmentative and Alternative Communication, 12(2), 78-87.

Beck, A. R., Fritz, H., Keller, \& Dennis M. (2000). Attitudes of school-aged children toward their peers who use Augmentative and Alternative Communication. Augmentative and Alternative Communication, 16(1), 13-26.

Bedrosian, J. L., Hoag, L. A., Calculator, S. N., \& Molineux B. (1992). Variables influencing perceptions of the communicative competence of an adult augmentative and alternative communication system user. Journal of Speech and Hearing Research, 35, 1105-1113.

Bender, L. F. (1980). Attitudes toward disabled people. Developmental Medicine and Child Neurology,_22, 427-428 (Editorial).

Beukelman, D. R.,\& Mirenda, P. (1992). Augmentative and Alternative Communication. Management of severe communication disorders in children and Adults. Baltimore: Paul Brookes Publishing Co.

Blockberger, S., Armstrong, R.W., O'Connor, A., \& Freeman, R. (1993). Children's attitudes toward a nonspeaking child using various augmentative and alternative communication techniques. Augmentative and Alternative Communication, 9(4), 243-250.

Dooley, D. (1995). Social Research Methods ( $3^{\text {rd }}$ ed.). Englewood Cliffs, NJ: Prentice-Hall, Inc.

Feldman, R. S. (1993). Understanding Psychology $\left(3^{\text {rd }}\right.$ ed.). New York: McGraw-Hill Inc.

Fiedler, C. R., \& Simpson, R. L. (1987). Modifying the attitudes of nonhandicapped high school students toward handicapped peers. Exceptional Children, 53, 342-349.

Goossens, C., Crain, S. S., \& Elder, P. S. (1994). Engineering the Preschool Environment for interactive symbolic communication. Birmingham, AL.: Southeast Augmentative Communication Conference Publications.

Gorenflo, C. W., \& Gorenflo, D. W. (1991). The effects of information and augmentative communication technique on attitudes toward nonspeaking individuals. Journal of Speech and Hearing Research, 34, 19-26.

Gorenflo, D. W., \& Gorenflo, C. W. (1997). Effects of synthetic speech, gender and perceived similarity on attitudes toward the augmented communicator. Augmentative and Alternative Communication, 13(2), 87-91.

Helander, E., Mendis, P., Nelson, G., \& Goerdt, A. (1989). Training in the community for people with disabilities. Geneva: World Health Organisation.

Higginbotham, D. J. (1989). The interplay of communication device output mode and interaction style between nonspeaking persons and their speaking partners. Journal of Speech and Hearing Disorders, 54, 320-333.

Hoag, L. A., \& Bedrosian J. L. (1992). Effects of speech output type, message length and reauditorization on perceptions of the communicative competence of an adult AAC user. Journal of Speech and Hearing, Research, 35, 1363-1366. 
Hoag, L. A., Bedrosian J. L., Johnson, D. E., \& Molineux, B. (1994). Variables affecting perceptions of social aspects of the communicative competence of an adult AAC user. Augmentative and Alternative Communication, 10(3), 129-137.

Horne, M.D. (1985). Attitudes Toward Handicapped Students. Hillsdale, NJ: Lawrence Earlbaum Associates.

Kalinowski, J. S., Lerman, J. W., \& Watt, J. (1991). A Preliminary examination of the perceptions of self and others in stutterers and nonstutterers. Journal of Fluency Disorders, 12, 317-331.

King, S.M., Rosenbaum, P., Armstrong, R. W., \& Milner, R. (1989). An epidemiological study of children's attitudes toward disability. Developmental Medicine and Child Neurology, 31, 237-245.

Kisanji, J. (1995). Growing up disabled. In P. Zinkin \& H. McConachie (Eds), Disabled children \& developing countries (pp.183-202). London: Cambridge University Press.

Kraat, A. W. (1987). Communication interaction between aided and natural speakers: $A$ state of the art report ( $2^{\text {nd }}$ ed.). Madison, WI: Trace Research and Development Centre, University of WisconsinMadison.

Light, J. (1988). Interaction involving individuals using Augmentative and Alternative Communication Systems: State of the Art and Future Directions. Augmentative and Alternative Communication, 4(2), 66-82.

Lloyd, L. L., Fuller, D. R., \& Arvidson, H. H. (1997). Augmentative and Alternative Communication. A handbook of principles and practices. Boston: Allyn and Bacon.

McCall, F., Markova, I., Murphy, J., Moodie, E., \& Collins, S. (1997). Perspectives on AAC systems by the users and by their communication partners. European Journal of Disorders of Communication, 32, 235-256.

McKinnon, S. L., Hess, C. W. \& Landry, R. G. (1986). Reactions of college students to speech disorders. Journal of Communication Disorders ${ }_{2} 19,75-82$.

NCSCET (National Commission on Special Needs in Education and Training). (1997). Education for all.
Public discussion document. Cape Town: University of the Western Cape.

O'Keefe, B. M., Brown, L., \& Schuller, R. (1998). Identification and Rankings of Communication Aid features by five groups. Augmentative and Alternative Communication, 14(1), 37-50.

Oppenheim, A. N. (1973). Questionnaire design and attitude measurement. London: Heinmann Educational Books Ltd.

Oppenheim, A. N. (1994). Questionnaire design, interviewing and attitude measurement. London: Printa Publishers.

Owen, K., \& Taljaard J.J. (1995). Handleiding vir die gebruik van Sielkundige en Skolastiese toetse van die $R G N$ [Manual of Psychological and Scholastic Tests of the Council for Humanities Research]. Pretoria: HSRC.

Rosenbaum, P. L., Armstrong, R. W., \& King, S. M. (1986). Children's attitudes toward disabled peers: A Self-report measure. Journal of Pediatric Psychology, 11(4), 517-530.

Schepis, M. M., \& Reid, D. H. (1995). Effects of a voice output communication aid on interactions between support personnel and an individual with multiple disabilities. Journal of Applied Behavior Analysis, 28(1), 73-77.

Uditsky, B. (1993). From integration to inclusion: The Canadian Experience. In R. Slee (Ed.): Is there a desk with my name on it? The Politics of Integration. London: The Falmer Press.

Voeltz, L. M. (1980). Children's attitudes toward handicapped peers. American Journal of Mental Deficiency, 84(5), 455-464.

Warrick, A. (1988). Sociocommunicative considerations within Augmentative and Alternative Communication. Augmentative and Alternative Communication, 4(1), 45-51.

Wisely, D. W., \& Morgan, S. (1981). Children's ratings of peers presented as mentally retarded and physically handicapped. American Journal of Mental Deficiency, 86(3), 281-286.

\section{Appendix A}

\section{CADAQ Statements}

\section{Affective Behavioural Items}

6 I would worry if Alan sat next to me in class.

9 I would be scared to talk to Alan.

13 I would be embarrassed to communicate like Alan does.

15 It would be fun to talk to Alan.

26 I feel upset when I see how Alan has to 'talk'.

10 I would like to talk to Alan.

12 I would tell my secrets to Alan.

16 Alan would be unwelcome at my birthday party.

18 If Alan was in my class I would like to do a project with him:

21 I would try to stay away from Alan if he came to my school.

28 Alan would not be my best friend.

31 I would like to go to 'The Spur' with Alan.

37 I would like Alan to sit next to me in class. 


\section{Cognitive Items}

2 . Our class works too quickly for Alan.

4. Alan would find it difficult to make friends at my school.

8. I think Alan has many friends.

17. Alan would get teased in our class.

20. Alan would be popular with the girls.

25. Alan would need lots of help in the classroom.

29. Alan had interesting things to say.

32. Alan most likely comes last in class.

33. Alan should be good with computers.

34. I do not think Alan has much fun.

36. Alan needs lots of help to tell a story.

\section{Communicative Competence}

1. Alan took an active part in the conversation.

3. Kim understood everything Alan said.

5. If I couldn't speak I would like to communicate like this.

7. I found it easy to understand what Alan meant.

11. There must be better ways for Alan to communicate.

14. It was easy to understand what Alan was 'saying'.

19. Alan could not communicate quickly enough.

22. Alan was frustrated communicating like that.

23. Alan was unable to say what he really wanted to.

24. Alan could answer Kim's questions quickly enough.

27. Kim did not always understand what Alan wanted to say.

30. The way Alan communicated with Kim resulted in some misunderstanding.

35. Alan could say exactly what he wanted to.

\section{Appendix B}

\section{Conversational Extract of the Videotape.}

Kim: Hello Alan

Alan: $\mathrm{Hi}, \mathrm{Kim}$

Kim: What have you been doing on your computer lately?

Alan: Making web-pages

Kim: What programme do you use?

Alan: Frontpage

Alan: What do you look up on Internet?

Kim: I look up information for school projects

Kim: How has school been lately?

Alan: O.K. But very busy

\section{Appendix C \\ Instructions to participants prior to and after viewing videotape $\mathrm{A}$ or $\mathrm{B}$.}

'As part of your theme on disability awareness you are about to watch a 5 minute video of Alan, a boy who has physical disabilities and is in Grade 6 at the school where I work. In the video, Alan is chatting to his new friend, Kim. Due to his disability Alan is not able to speak clearly and he communicates in other ways. All I ask is that you do not discuss the video with your friends while we are watching it and remember to watch it carefully as you are going to answer some questions when we have finished watching it'.

\section{The videotape was then screened. Group 1 watched Videotape A whereas Group 2 watched Videotape B and the participants were then given the following instructions:}

'I am now going to hand out the questionnaires and pencils. Please don't chat about the video until all the questions have been answered. You will then be able to ask me any questions you want to about Alan. In the meantime you can tick the block next to your age and whether you are a boy or girl. Please don't write your name on the questionnaireś and neither your teachers nor I will know which one is your questionnaire. Remember there are no right.or wrong answers and this is not for marks. I want you to think about the video while you answer the questions. I will read each question and you must tick the answer that best shows how you feel. Please make only one tick per question and don't leave any questions out. Let's start with the first example....' 